Review

\title{
A Review on Direct Electrochemistry of Catalase for Electrochemical Sensors
}

\author{
Periasamy Arun Prakash, Umasankar Yogeswaran and Shen-Ming Chen* \\ Department of Chemical Engineering and Biotechnology, National Taipei University of Technology, \\ No.1, Section 3, Chung-Hsiao East Road, Taipei 106, Taiwan (ROC); \\ E-Mails: arunprakash.p@gmail.com (P.A.P.); uyogesh@gmail.com (U.Y.) \\ * Author to whom correspondence should be addressed; E-Mail: smchen78@ms15.hinet.net; \\ Tel: +886 2270 17147; Fax: +886227025238
}

Received: 20 January 2009; in revised version: 3 March 2009 / Accepted: 13 March 2009 / Published: 13 March 2009

\begin{abstract}
Catalase (CAT) is a heme enzyme with a $\mathrm{Fe}^{(\mathrm{III} / \mathrm{II})}$ prosthetic group at its redox centre. CAT is present in almost all aerobic living organisms, where it catalyzes the disproportionation of $\mathrm{H}_{2} \mathrm{O}_{2}$ into oxygen and water without forming free radicals. In order to study this catalytic mechanism in detail, the direct electrochemistry of CAT has been investigated at various modified electrode surfaces with and without nanomaterials. The results show that CAT immobilized on nanomaterial modified electrodes shows excellent catalytic activity, high sensitivity and the lowest detection limit for $\mathrm{H}_{2} \mathrm{O}_{2}$ determination. In the presence of nanomaterials, the direct electron transfer between the heme group of the enzyme and the electrode surface improved significantly. Moreover, the immobilized CAT is highly biocompatible and remains extremely stable within the nanomaterial matrices. This review discusses about the versatile approaches carried out in CAT immobilization for direct electrochemistry and electrochemical sensor development aimed as efficient $\mathrm{H}_{2} \mathrm{O}_{2}$ determination. The benefits of immobilizing CAT in nanomaterial matrices have also been highlighted.
\end{abstract}

Keywords: Direct electrochemistry; catalase; electrocatalysis; hydrogen peroxide; electrochemical sensors; nanomaterials. 


\section{Introduction}

The study of the direct electron transfer pathways of redox proteins or enzymes is very significant in understanding the redox proteins, as well as in development of enzyme biosensors, biofuel cells and biomedical devices [1]. An in-depth study of the direct electrochemistry (DET) of heme enzymes provides satisfactory information regarding these bioelectrocatalysts (enzymes) and their major roles in electrocatalysis [2-6]. In the past decades, numerous works have been done to study the DET of various redox proteins and enzymes at modified electrodes. In 1977, a new gateway for protein direct electrochemistry was opened, when two groups, Yeh et al. and Eddowes et al. [7,8], independently reported the phenomenon of reversible electron transfer at a cytochrome c (cyt c) modified electrode. Since then, a large number of proteins and enzymes were successfully immobilized on a variety of biological and chemical matrices. Recently, Wolenberger et al. have reviewed direct protein electrochemistry using isolated enzymes and enzyme-protein couples [9]. The studies of redox proteins' direct electrochemistry are thus important in understanding the mechanism of electron transfer between immobilized proteins and the electrodes.

On the other hand, an electrochemical sensor is a device in which a biochemical recognition process is coupled to an appropriate electrochemical transducer where one of the electrochemical transducer components is the electrode. To enhance the efficiency of the transducer, the electrode surfaces have been modified either using redox active compounds or bio-components like enzymes and proteins. Among enzymes, nearly 3,000 wild type enzymes are known and 1,060 of them are oxidoreductases. The oxidoreductase enzymes family are very important since they catalyze $\mathrm{H}_{2} \mathrm{O}_{2}$ reduction within the cells. During this reduction process, $\mathrm{H}_{2} \mathrm{O}_{2}$ is reduced to $\mathrm{H}_{2} \mathrm{O}$ and molecular $\mathrm{O}_{2}$ without forming free radicals. This reaction is mainly catalyzed by catalase (CAT) present in the red blood cells of mammals. CAT is a heme-containing redox protein with ferritoprotoporphyrin IX at its redox centre which belongs to the oxidoreductase family class [10]. It possesses a heme prosthetic group at its active site with metallic iron $\left(\mathrm{Fe}^{\mathrm{III}}\right)$. The catalytic ability of CAT to reduce $\mathrm{H}_{2} \mathrm{O}_{2}$ has been applied in the development of $\mathrm{H}_{2} \mathrm{O}_{2}$ sensors [11]. In order to investigate this catalytic ability of CAT in detail, the direct electrochemistry of CAT at the transducer surface has to be examined, but earlier studies showed that immobilization of CAT directly on the bare electrode surface lead to poor electron transfer [12]. This may be due to the fact that the $\mathrm{Fe}^{\text {(III/II) }}$ group gets deeply buried inside the huge structure of CAT. In order to achieve better electron transfer, CAT has been immobilized on various modified electrode surfaces. The electrode surfaces were modified either with surfactants, biopolymers, organic polymers, hydrogels, sol-gels or dendrimers, respectively [15-25]. Though noticeable electron transfer was observed with a few modified electrodes, the majority of them fail to promote the electron transfer process. This might be due to the diminished contact between CAT and such modified matrices. To overcome these problems, the bioelectric contact between CAT and the bare electrode was improved with the implementation of nanomaterials [29]. It is a well known fact that, with large surface area and highly porous network, nanomaterials are well suited for the entrapment of biological molecules [49-51]. Further, proteins or enzymes can be easily immobilized at these nanomaterials without any damage. In recent years, many researchers have attempted to immobilize CAT on various nanomaterial modified electrode surfaces. Their results ultimately illustrate that CAT immobilized on nanomaterial matrices possesses enhanced electron transfer and 
excellent catalytic activity. However, a survey of the literature shows that no one has presented a review on the direct electrochemistry of CAT and the influence of nanomaterials on the direct electron transfer of CAT. Consequently, in the present review we have discussed the direct electrochemistry of CAT on various modified electrode surfaces, both in the presence and absence of nanomaterials. This review mainly highlights the various electrode fabrication methods, their electrochemical characterizations, miscellaneous enzyme immobilization strategies used by researchers in the present and past decades, along with the benefits of using nanomaterials as enzyme immobilization matrices.

\section{Nanomaterial Free Matrices for CAT Immobilization - Versatile Approaches}

\subsection{Polyelectrolyte Encapsulated CAT}

Earlier attempts were made by researchers to immobilize CAT onto various nanomaterial free matrices. Caruso and co-workers carried out a simple yet versatile approach to encapsulate CAT crystals within polymer multilayer capsules via the stepwise regular assembly of oppositely charged polyelectrolytes, poly(styrenesulfonate) (PSS) (negatively charged) and poly(allylamine hydrochloride) (PAH) (positively charged), using biocrystals as templates [13]. The schematic representation of the process of enzyme encapsulation into the polymer films is shown in Figure 1. They examined the activity and stability of CAT present inside the polymer multilayer films through proteolysis. They observed that the polymer encapsulated CAT retained $100 \%$ of its activity, even after 100 min incubation with protease, whereas polymer uncoated CAT loses more than $90 \%$ of its initial activity within 100 min under the same conditions.

Yu et al. employed a similar approach to encapsulate CAT into polyelectrolytes, PAH and PSS respectively [14]. They investigated the direct electron transfer behavior and electrocatalytic response of polyelectrolyte encapsulated CAT to $\mathrm{H}_{2} \mathrm{O}_{2}$ reduction. The polyelectrolyte encapsulated CAT displays 4.5 times higher electrocatalytic response to $\mathrm{H}_{2} \mathrm{O}_{2}$ than non-encapsulated and solubilized CAT. However, the relative increase in catalytic response at the former was not proportional to the amount of enzyme deposited, since the entire CAT molecules were not found in their electrocatalytic active site. This might be due to the reason that the distance between the CAT molecules and the electrode surface gets significantly increased after polyelectrolyte encapsulation. Furthermore, they observed through their detailed studies that, with increases in precursor polyelectrolyte layer number, the current response to $\mathrm{H}_{2} \mathrm{O}_{2}$ decreased significantly, while the electrode response time increased. In contrast, implementation of fewer polyelectrolyte layers lead to sensitive and fast response in $\mathrm{H}_{2} \mathrm{O}_{2}$ determinations. This approach of encapsulating CAT micro crystals into polyelectrolyte layers for biosensing provides a versatile approach to prepare high enzyme content films with improved enzyme activities. 
Figure 1. Schematic representation of the process involved in the encapsulation of CAT into polymer multilayers using biocrystals as templates. (Steps 1,2) stepwise deposition of poly electrolyte layers; (Step 3) Exposure of the enzyme to solutions of $\mathrm{pH}>6$ or acidic solution $(\mathrm{pH}<4)$, which results in the morphology change of the polymer capsule accompanied by the solubilisation of the enzyme; (Step 4) Exposure of the enzyme to solutions of $\mathrm{pH}>11$ leads to the release of the enzyme by rupturing of the polymer capsule; (Step 5) Exposure of the encapsulated enzyme to an oxidizing solution results in the decomposition of the enzyme and thus enzyme expelled from the interior of the capsule through the polymer walls, leaving behind the hollow polymer capsules (reproduced with permission from Caruso et al. Langmuir 2000, 16, 1485-1488).
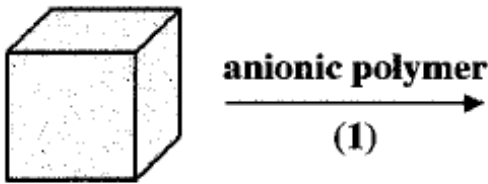

(1)

\section{Enzyme Crystal}

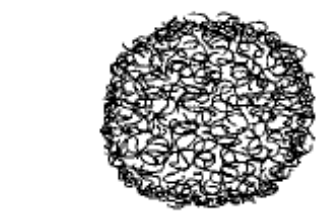

Hollow Polymer Capsule

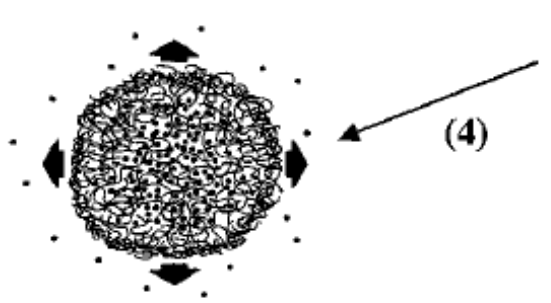

Enzyme Release

(5)

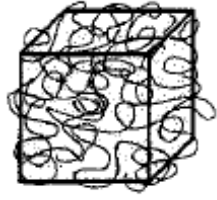

cationic polymer

(2)

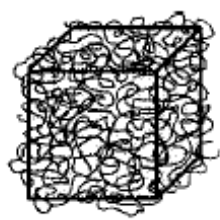

(1), (2), etc.

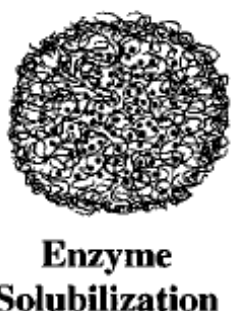

pH change

(3)

Polymer Multilayer-Coated

Enzyme Crystal

\subsection{Surfactant Modified Matrices for CAT Immobilization}

In an alternative approach, Chen et al. attempted to immobilize CAT onto cationic surfactant, (didodecyldimethylammonium bromide, DDAB) liquid crystal films [15]. They revealed through their results that the electron transfer of CAT is greatly improved in the presence of DDAB. The electron transfer rate constant $\left(k_{\mathrm{s}}\right)$ was observed to be $3.0 \pm 0.4 \mathrm{~s}^{-1}$. However, their circular dichroism (CD) results illustrated that the conformation of CAT gets slightly perturbed by the hydrophobic nature of DDAB (Figure 2). The CD spectrum of CAT exhibits a negative peak at $237 \mathrm{~nm}$, whereas for CATDDAB film it was observed at $232 \mathrm{~nm}$. The negative peak at $232 \mathrm{~nm}$ was regarded as the shift from $237 \mathrm{~nm}$ of CAT film alone. 
Figure 2. CD spectra of CAT (- - ) DDAB (-- $)$, CAT-DDAB $(-)$ films. CAT was prepared in $\mathrm{pH} 6.1,10 \mathrm{mM}$ phosphate buffer solution (PBS) with $50 \mathrm{mmol}: 1 \mathrm{KCl}$. Temperature: $25^{\circ} \mathrm{C}$ (reproduced with permission from Chen et al. Biosens. Bioelectron. 2001, 16, 115-120)

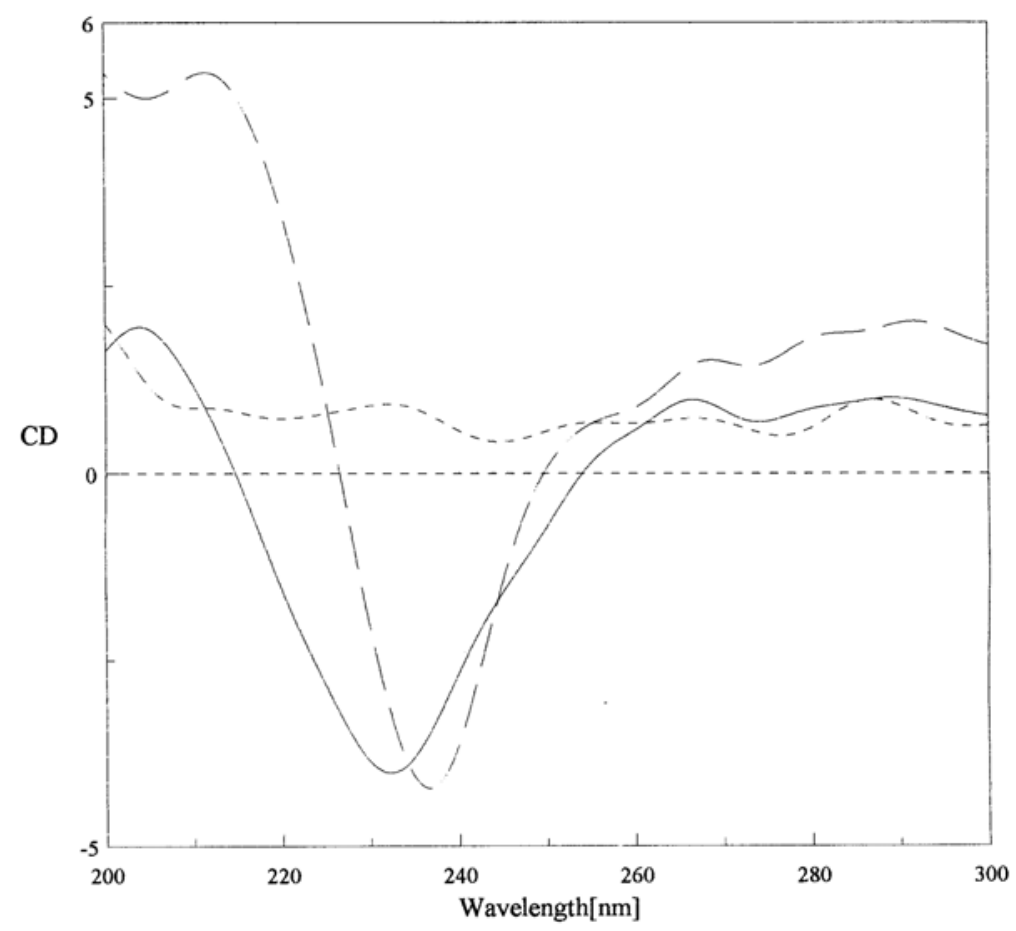

Gebica et al. also studied the interaction of the surfactant sodium bis(2-ethylhexyl) sulfosuccinate (AOT) with CAT and horseradish peroxidase (HRP) [16]. They studied comparatively the properties of CAT and HRP entrapped into AOT/n-heptane with those in aqueous solutions of AOT. Their detailed studies illustrate that the secondary structure of CAT changed significantly in the presence of aqueous micellar solutions of AOT and the activity of CAT was completely lost. Interestingly, the secondary structure of CAT remains unchanged in the AOT/n-heptane reverse micelles.

\subsection{Immobilization of CAT at Various Polymers and Gel Matrices}

Other than surfactants, CAT has been immobilized in various matrices like biopolymers, organic polymers, hydrogels and sol-gels, respectively. Huang and co-workers attempted to immobilize heme proteins like myoglobin $(\mathrm{Mb})$, hemoglobin $(\mathrm{Hb}), \mathrm{HRP}$ and CAT into chitosan (CS) film modified pyrolytic graphite (PG) electrodes [17]. They obtained stable voltammogramms for MB, Hb and HRP films, whereas less stable voltammogramms were obtained in the case of CAT-CS films. Furthermore, compared to other protein-CS films, the electron transfer process also happens at a much slower rate in CAT-CS films and the stability was relatively very poor. Lu et al. have successfully immobilized CAT on polyacrylammide (PAM) hydrogel film-coated PG electrodes [18]. They investigated the direct voltammetric and electrocatalytic behavior of these CAT incorporated PAM films. They observed that the electron transfer of CAT was greatly facilitated in the microenvironment of PAM films. However, the electron transfer of these CAT-PAM films was much smaller and relatively less stable than CAT- 
CS films described above. Through UV-vis spectroscopy, they observed the position change of the Soret band for CAT-PAM films (Figure 3). They revealed through their results that CAT in dry PAM films retains a secondary structure that is the same as the native state of CAT in dry CAT films. Further, CAT in PAM films essentially retains its native state in buffers at medium $\mathrm{pH}$. When the $\mathrm{pH}$ was more acidic or more basic, the Soret band showed a blue-shift with some distortion. As shown in Figure 3(f), substantial denaturation of CAT in PAM films takes place at $\mathrm{pH}$ 3.0. This illustrates the poor stability of CAT-PAM films at acidic $\mathrm{pH}$ values. Nevertheless, CAT-PAM shows good catalytic activity towards $\mathrm{H}_{2} \mathrm{O}_{2}$ reduction in the concentration range $0.4-0.8 \mathrm{mM}$ (See Table 1).

Figure 3. UV-vis absorption spectra of (a) dry CAT film, (b) dry CAT-PAM film, and CAT-PAM films in different $\mathrm{pH}$ buffer solutions: (c) $\mathrm{pH} 7.0$; (d) $\mathrm{pH} 5.0$; (e) $\mathrm{pH} 9.0$ and (f) pH 3.0 (reproduced with permission from Lu et al. Biophys. Chem. 2003, 104, 623-632).

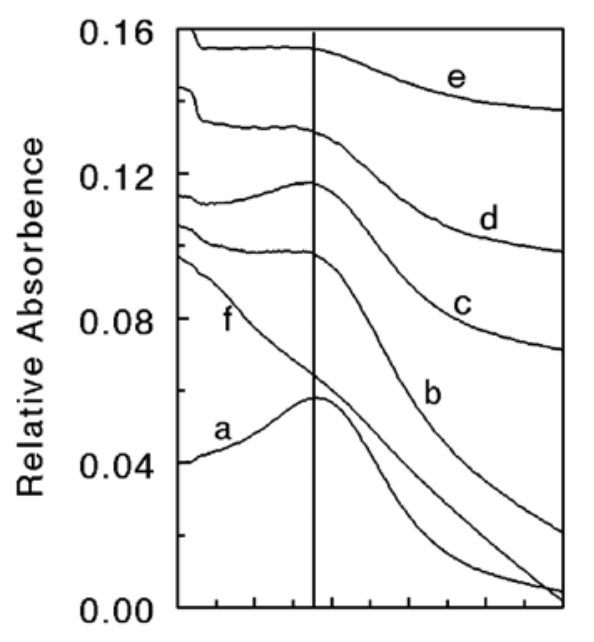

370390410430450470

$\lambda / \mathrm{nm}$

Li et al. investigated the direct voltammetric behavior of heme proteins CAT and HRP immobilized on methyl cellulose (MC) modified edge-plane pyrolytic graphite electrodes [19]. Both CAT-MC and HRP-MC films displayed a good response to $\mathrm{H}_{2} \mathrm{O}_{2}$ reduction in the concentration range of 0.02 to 0.12 $\mathrm{mM}$ and 0.02 to $0.11 \mathrm{mM}$, respectively (See Table 1). However, the electron transfer rate observed on CAT-MC films was relatively lower than that of CAT-CS and CAT-PAM films. Li et al. also successfully immobilized CAT and $\mathrm{Hb}$ onto collagen modified PG electrodes [20]. Though they noticed direct electron transfer in these protein-collagen films, the redox peak potential of CATcollagen films was found to be more negative than those of Hb-collagen films. This may be likely due to the reason that the larger polypeptide chains of CAT needs more active energy than $\mathrm{Hb}$ to electrochemically reduce at the PG electrodes. Moreover, Hb-collagen films were found to be more stable than CAT-collagen films. The reason for the greater stability of Hb-collagen films may be due to the electrostatic interactions between the oppositely charged groups present in collagen and $\mathrm{Hb}$ films. In addition, the hydrophobic and hydrogen-bond interactions between the collagen and $\mathrm{Hb}$ films further help to maintain the stability of these films. However, the reasons for the poor stability of CAT-collagen films were not reported. Further results show that, a more facile electron transfer 
process occurs at a much faster rate with Hb-collagen films than CAT-collagen films, which is obvious from the reported $k_{\mathrm{s}}$ values, $\left(46 \pm 6 \mathrm{~s}^{-1}\right)$ and $\left(31 \pm 3 \mathrm{~s}^{-1}\right)$, respectively.

$\mathrm{Wu}$ et al. investigated the direct electrochemistry of heme proteins $\mathrm{Mb}, \mathrm{Hb}, \mathrm{HRP}$ and CAT entrapped in silk fibroin (SF) films [21]. Among various protein-SF films, CAT-SF films relatively possess lower $k_{\mathrm{s}}$ value $\left(0.34 \mathrm{~s}^{-1}\right)$. This indicates that, much slower electron transfer process occurs at CAT-SF films. In contrast, the amperometric i-t measurement results reveal that, both HRP-SF and CAT-SF films were more active than Mb-SF and $\mathrm{Hb}-\mathrm{SF}$ films towards the catalytic reduction of $\mathrm{H}_{2} \mathrm{O}_{2}$ (Figure 4).

Figure 4. Amperometric i-t responses observed at different heme-proteins-SF/GCEs at $0.2 \mathrm{~V}$ in $10 \mathrm{ml}$ of PBS pH 7.0 for $10 \mu \mathrm{l}$ injection of $22 \mathrm{mM} \mathrm{H}_{2} \mathrm{O}_{2}$ for every $80 \mathrm{~s}$ : (a) SF films; (b) Mb-SF films; (c) Hb-SF films; (d) CAT-SF films; and (e) HRP-SF films (reproduced with permission from Wu et al. Anal. Chim. Acta 2006, 558, 179-186).

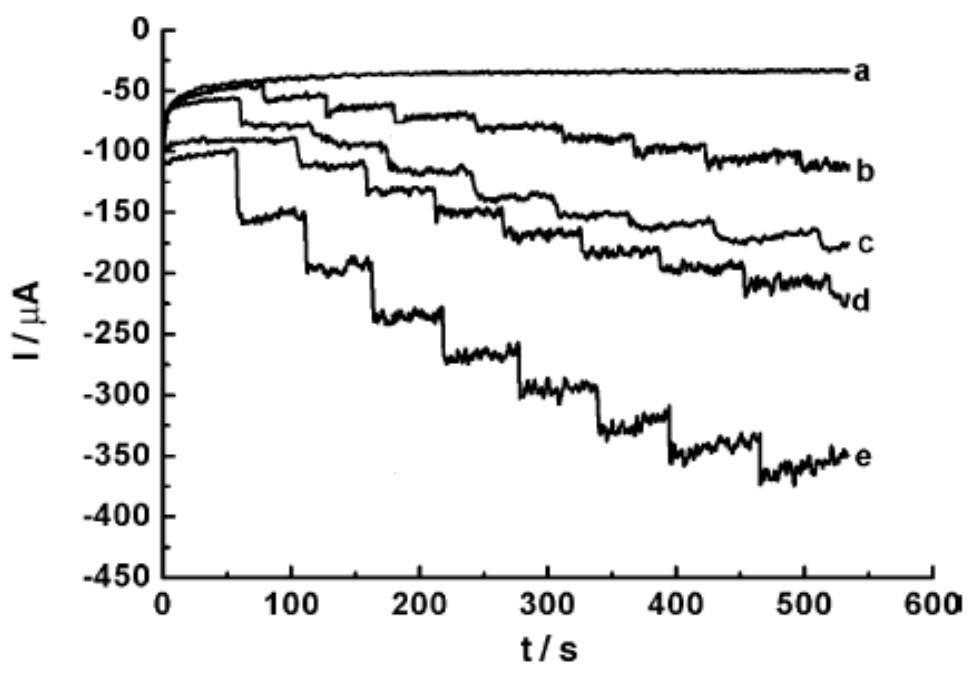

From the calibration curves for $\mathrm{H}_{2} \mathrm{O}_{2}$ determination (not shown), the linear range of $\mathrm{H}_{2} \mathrm{O}_{2}$ was observed to be 0.004 to $0.085 \mathrm{mM}$ for $\mathrm{Mb}-\mathrm{SF}$ films, 0.003 to $0.091 \mathrm{mM}$ for $\mathrm{Hb}-\mathrm{SF}$ films, 0.002 to $0.354 \mathrm{mM}$ for HRP-SF films and 0.003 to $0.158 \mathrm{mM}$ for CAT-SF films, respectively.

In an alternative approach, Sun et al. immobilized heme proteins $\mathrm{Hb}, \mathrm{Mb}$ and $\mathrm{CAT}$ into an organic polymer matrix, poly (N-isopropylacrylamide-co-3-methacryloxypropyltrimethoxysilane) (PNM) film coated glassy carbon electrode (GCE) [22]. All three protein-PNM films exhibit a facile electron transfer process, which is obvious from the obtained $k_{\mathrm{s}}$ values of 16, 17 and $20 \mathrm{~s}^{-1}$ for Hb-PNM, CATPNM and Mb-PNM films respectively. However, the stability of CAT-PNM films was much lower than $\mathrm{Hb}$ and $\mathrm{Mb}$ containing PNM films. CAT-PNM films show good catalytic activity towards $\mathrm{H}_{2} \mathrm{O}_{2}$ in the concentration range $0.002-0.035 \mathrm{mM}$ (See Table 1).

The direct electrochemistry of CAT immobilized in silica sol-gel in the presence of cysteine on gold $\mathrm{Au}$ ) electrode was reported by Di et al. [23]. They confirmed the different surface morphology between silica sol-gel matrices with and without CAT through AFM studies. Figure 5 shows the AFM image of sol-gel matrix without CAT and with CAT. In their detailed study, they used this CAT/cysteine/Si sol-gel modified electrode for the determination of $\mathrm{H}_{2} \mathrm{O}_{2}$ in the range 0.001 to 0.03 $\mathrm{mM}$ with a detection limit of $0.4 \mu \mathrm{M}$, respectively (See Table 1). Further, they investigated the 
interaction of CAT and aluminium $\left(\mathrm{Al}^{3+}\right)$ ions. They observed that, the electrocatalytic activity of CAT increased with the addition of $\mathrm{Al}^{3+}$ ions. Their detailed voltammetry and fluorescence spectroscopy results also confirms that, the addition of $\mathrm{Al}^{3+}$ ions leads to conformational changes in CAT molecule, which might be the reason for the improved catalytic activity of CAT.

Figure 5. AFM images of: (a) Cysteine/Silica sol-gel and; (b) CAT/cysteine/Si sol-gel modified Au electrodes (reproduced with permission from Di et al. Biosens. Bioelectron. 2006, 22, 247-252).

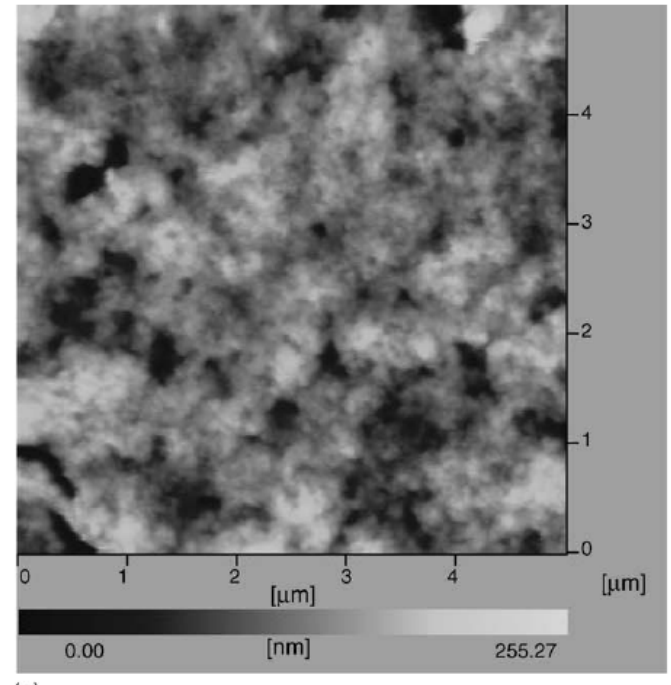

(a)

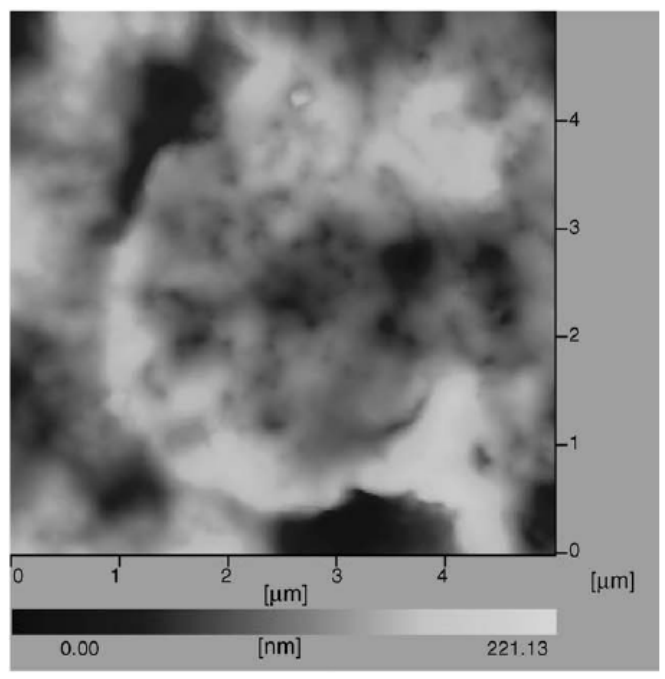

(b)

Recently Wang et al. immobilized the heme proteins $\mathrm{Hb}, \mathrm{Mb}$ and $\mathrm{CAT}$ into agarose hydrogel films [24]. They also investigated the effects of 1-butyl-3-methylimidazolium tetrafluoroborate ([bmim $]\left[\mathrm{BF}_{4}\right]$ ) along with a small amount of water on the direct electrochemistry and bioelectrocatalysis of the entrapped heme proteins. Their CV results provide strong evidence that CAT entrapped in agarose films exhibits direct electron transfer and retains its electrochemical activity in $[\mathrm{bmim}]\left[\mathrm{BF}_{4}\right]$ solution. A more facile electron transfer process occurs at CAT-agarose films $\left(k_{\mathrm{s}}=\right.$ 49.1 \pm 9.3$)$ than $\mathrm{Hb}$-agarose $\left(k_{\mathrm{s}}=36.1 \pm 7.3\right)$ and Mb-agarose $\left(k_{\mathrm{s}}=29.1 \pm 7.0\right)$ films respectively. Further, CAT-agarose films show good catalytic response towards $\mathrm{H}_{2} \mathrm{O}_{2}$ in the concentration range $0.001-$ $0.818 \mathrm{mM}$ (See Table 1). The Michaelis-Menten constant $\left(K_{\mathrm{m}}\right)$ for CAT-agarose films $(317 \pm 77 \mu \mathrm{M})$ is two folds smaller than $\mathrm{Hb}$ and $\mathrm{Mb}$, which indicates that the CAT entrapped in agarose film exhibits a higher affinity for $\mathrm{H}_{2} \mathrm{O}_{2}$.

\subsection{Dendrimer Matrices for CAT Immobilization}

Shen et al. successfully used a layer-by-layer assembly technique to immobilize $\mathrm{Hb}, \mathrm{Mb}$ and CAT with polyamidoamine (PAMAM) dendrimers on different solid surfaces [25]. As well known, at $\mathrm{pH} 7$ protonated PAMAM possesses positive surface charges, whereas the proteins have net negative surface charges. Thus, layer-by-layer $\{\text { PAMAM-protein }\}_{\mathrm{n}}$ films were assembled with alternate adsorption of oppositely charged PAMAM and proteins from their aqueous solutions mainly by electrostatic interaction. The assembly process was monitored by QCM, UV-vis spectroscopy and CV. 
The growth of the protein multilayer films was regular and linear, whereas the electroactivity of the films extended only to a few bilayers. CVs of \{PAMAM-protein $\}_{n}$ films showed a pair of well-defined and nearly reversible peaks which are characteristic of the heme $\mathrm{Fe}^{\text {(III)/(II) }}$ redox couples of the corresponding proteins. Although $\{\text { PAMAM-Hb }\}_{n}$ and $\{\text { PAMAM-Mb }\}_{n}$ films showed very similar properties, $\{\text { PAMAM-CAT }\}_{n}$ films displayed dissimilar properties. The substrates with biological or environmental significance, such as oxygen, $\mathrm{H}_{2} \mathrm{O}_{2}$, trichloroacetic acid, and nitrite, were catalytically reduced at $\{\text { PAMAM-protein }\}_{\mathrm{n}}$ film electrodes. This shows the potential applicability of the $\{\text { PAMAM-protein }\}_{\mathrm{n}}$ films as new types of biosensors or bioreactors. Both the electrochemical and electrocatalytic activity of $\{\text { PAMAM-protein }\}_{n}$ films can be tailored precisely by controlling the number of bilayers or the film thickness. Among various protein-PAMAM films, CAT incorporated PAMAM films showed poor stability and the catalytic response towards $\mathrm{H}_{2} \mathrm{O}_{2}$ was limited only to two layers. The previous experimental results showed that greater the distance between the enzyme and the electrode surface lesser will be the stability. The CAT with greater molecular dimension (diameter $10.5 \mathrm{~nm}$ ) also experience weaker interactions with PAMAM, which could be partly responsible for the less stability of $\{\text { PAMAM-CAT }\}_{\mathrm{n}}$ films.

As discussed in Section 2, CAT immobilized on various nanomaterial-free matrices possesses unique characteristics like facile electron transfer, good catalytic activity, fast response and appreciable stability. More immense evolution in the characteristics of CAT based sensors has been achieved in the recent years with the implementation of various nanomaterial matrices. The utilization of nanomaterials as CAT immobilization matrices narrowed the difficult tasks that existed over the past decades in the achievement of direct electrochemistry. Besides these, the long term stability of such nanomaterial-incorporated CAT films has promoted their wide applications in various fields. The significant advancements in the implementation of nanomaterial matrices for CAT immobilization towards the development of efficient $\mathrm{H}_{2} \mathrm{O}_{2}$ sensors are explained in detail in the subsequent section.

\section{Nanomaterial Matrices used for CAT Immobilization}

The direct electrochemistry of CAT at various nanomaterial modified matrices is discussed in the following sections.

\subsection{CAT Immobilized in Single-wall Carbon Nanotubes (SWCNTs) Matrices}

SWCNTs with high tensile strength and unique ability to grow on various electrode surfaces have advanced their applications in electrochemical sensor development. Recently, Salimi et al. reported the lowest ever detection limit of $10 \mathrm{pM}$ determination of $\mathrm{H}_{2} \mathrm{O}_{2}$ with an excellent sensitivity (47.6 nA $\mathrm{pM}^{-1}$ ) at an $\mathrm{NAD}^{+}$strongly adsorbed SWCNTs modified electrode [26]. This shows the excellent application of SWCNTs matrices towards the direct determination of $\mathrm{H}_{2} \mathrm{O}_{2}$. Moreover, the exceptional properties of SWCNTs have made them extremely suitable for enzyme immobilization and thus they are exclusively used for enzyme based biosensor development [27,28]. Interestingly, Wang and coworkers reported the direct electrochemistry of CAT at SWCNTs-Au electrode surface [29]. Their detailed electrode fabrication procedure involves the following steps: about $1 \mathrm{mg}$ of purified SWCNTs was dissolved in $10 \mathrm{~mL}$ of $N, N$-dimethylformamide and the whole mixture was ultrasonicated until a 
uniform dispersion was obtained. About $15 \mu \mathrm{L}$ of this SWCNTs suspension was casted on a clean Au electrode surface and dried under an infrared lamp. This SWCNTs-Au electrode was then immersed into $50 \mu \mathrm{M}$ CAT in pH $5.9 \mathrm{PBS}$ and kept for $20 \mathrm{~min}$. For better performance, the CAT concentration was optimized as $8 \mu \mathrm{M}$ to $80 \mu \mathrm{M}$ respectively.

Their CV results illustrate that CAT adsorbed on bare Au electrode surface exhibits no significant redox peaks (Figure 6a). However, the SWCNTs-Au modified electrode with CAT exhibits a pair of well defined quasi reversible peaks at $-0.414 \mathrm{~V}$ vs. SCE with a peak potential separation $(\Delta \mathrm{Ep})$ value of $32 \mathrm{~V}$ (Figure 6b). Though in the absence of CAT, no noticeable peaks were observed for the SWCNTs modified Au electrode, considerable back ground current was found (Figure 6c). This provides evidence that the surface area of the Au electrode has been significantly increased in the presence of SWCNTs and this indeed enhanced the electron transfer process of CAT. Moreover, from their $\mathrm{pH}$ studies it was obvious that the catalytic peak current of CAT negatively shifted with $\mathrm{pH} 3.1$ to 8.9 with a slope of $36 \mathrm{~V}$. This reveals that the $\mathrm{Fe}^{(\mathrm{III} / \mathrm{II})}$ redox couple of CAT involves a one proton and two electron transfer process.

Figure 6. (a) CVs of CAT (adsorbed from a $50 \mu \mathrm{M}$ CAT solution) at a bare Au electrode (b) SWCNTs-Au modified electrode with CAT and (c) SWCNTs-Au modified electrode without CAT. The electrolyte solution used was $0.05 \mathrm{M}$ PBS pH 5.9 and the scan rate employed was $0.1 \mathrm{~V} \mathrm{~s}^{-1}$ (reproduced with permission from Wang et al. Electroanalysis 2004, 16, 627-632).

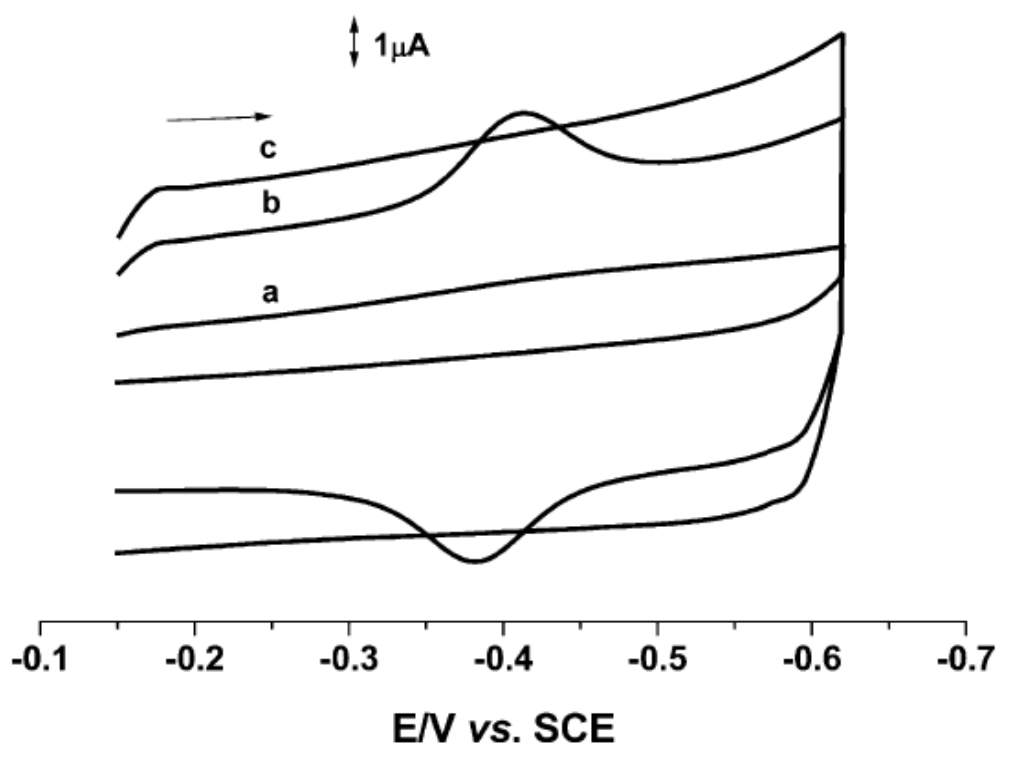

Moreover, their catalytic activity studies show that the CAT immobilized on SWCNT matrices exhibits a good response towards $\mathrm{H}_{2} \mathrm{O}_{2}$ in the concentration range $0.7 \mathrm{mM}$ to $1.1 \mathrm{mM}$, respectively. All the above studies show that CAT has been successfully immobilized on SWCNTs, and the direct electron transfer and catalytic activity are greatly enhanced in the presence of SWCNTs. The analytical data have been given in Table 1 . 


\subsection{CAT Immobilized in a SWCNTs-CS Matrix}

CS is a multifunctional biopolymer which possesses exceptional properties like excellent filmforming ability, good adhesion, biocompatibility, high mechanical strength and has thus been used to immobilize biomolecules in recent years [30-33]. In order to increase the contact area between enzyme and SWCNTs, for better sensor sensitivity and stability, CS was widely employed to wrap SWCNTs. [34]. Jiang et al. observed that the incorporation of CS into SWCNTs lead to significant enhancements in the mechanical strength, tensile strength and conductivity of SWCNTs [35]. They have successfully immobilized CAT onto this SWCNTs-CS composite matrix and thereby observed the direct electrochemistry of CAT. In their detailed electrode fabrication process, SWCNTs were dispersed in $0.5 \%$ by weight $\mathrm{CS}$ solution and sonicated until a $0.5 \mathrm{mg} \mathrm{mL} \mathrm{m}^{-1}$ black suspension was obtained. About $5 \mu \mathrm{L}$ of this SWCNT suspension was casted onto a cleaned GCE surface with a microsyringe, and dried at room temperature. The SWCNTs-GCE was immersed overnight in $10 \mathrm{mg}$ $\mathrm{mL}^{-1} \mathrm{CAT}$ solution at $4^{\circ} \mathrm{C}$.

CV studies show that SWCNTs-CS-CAT-GCE exhibits a pair of well defined redox peaks at ca. $-0.45 \mathrm{~V}$ and $-0.5 \mathrm{~V}$. The different scan rate studies explain that a surface confined process occurs at the modified electrode surface. From the average surface coverage concentration $(\Gamma)$ value of CAT $\left(16.4 \mathrm{nmol} \mathrm{cm} \mathrm{cm}^{-2}\right)$ they confirmed that a monolayer of CAT has been formed over the SWCNTs modified electrode. The $\mathrm{pH}$ studies show that a one electron/one proton coupled reaction occurs at SWNTs-CS-CAT-GCE. These results clearly illustrate that direct CAT electrochemistry has occurred in the SWCNTs-CS matrix. They further observed through their CV studies that SWNTs-CS-CATGCE exhibits a steady increase in cathodic reduction peak current at $-0.50 \mathrm{~V}$ for every substantial addition of $\mathrm{H}_{2} \mathrm{O}_{2}$ to the analyte solution (Figure 7). The linear concentration range was observed to be 5-50 $\mathrm{mM} \mathrm{H}_{2} \mathrm{O}_{2}$. The sensitivity was $6.32 \mu \mathrm{A} \mathrm{mM}^{-1} \mathrm{~cm}^{-2}$ and detection limit was $2.5 \mu \mathrm{M}$, respectively (see Table 1). The following catalytic mechanism explains in detail about the electrocatalysis process that occurs at the electrode.:

$$
\begin{array}{lll}
\text { Heme } \mathrm{Fe}^{(\mathrm{III})}+\mathrm{H}_{2} \mathrm{O}_{2} & \longrightarrow & \text { Compound I }+\mathrm{H}_{2} \mathrm{O} \\
\text { Compound } \mathrm{I}+2 \mathrm{H}^{+}+2 \mathrm{e}^{-} & \longrightarrow & \text {Heme Fe }^{(\mathrm{III})}
\end{array}
$$

The electron transfer process becomes much more facile at SWCNTs platform, which was obvious from the very high $k_{\mathrm{s}}$ value of $118 \mathrm{~s}^{-1}$ respectively. The $k_{\mathrm{s}}$ value observed at SWCNTs-CS-CAT-GCE was relatively higher than the nanomaterial free matrix modified electrodes [15,20-22,24] reported in Section 2.

\subsection{CAT Immobilized in Nafion-nano Gold-MWCNT Matrices}

Zhou et al. reported the direct electrochemistry of CAT on multiwalled carbon nanotubes (MWCNTs) and gold nanoparticles (GNPs) modified pyrolitic graphite electrode (PGE) [36]. MWCNTs and GNPs provided an extremely stable microenvironment for the entrapped CAT molecule. Colloidal Au was prepared with slight modification according to the procedure of Frens et al. [37], and MWCNTs was pretreated to introduce carboxylic acid groups on the surface of CNTs 
[38]. The pretreated MWCNTs were dispersed in $1 \mathrm{mg} \mathrm{mL}^{-1}$ of $1 \%$ Nafion (NF) solution. The NFCAT-GNP-MWCNTs-PGE was prepared by the following procedure: Initially a $6 \mathrm{~mL}$ mixture of MWCNTs and $1 \%$ NF solution was dropped on the surface of a cleaned PGE and dried at room temperature. Another $6 \mathrm{~mL}$ of a mixture of CAT $(10 \mathrm{mg}$ of CAT in $1 \mathrm{~mL}$ of $0.1 \mathrm{M} \mathrm{pH} 6.98 \mathrm{PBS})$ and GNP ( $\mathrm{v}=\mathrm{v} 1 / 4$ 1:1) solution was dropped above the MWCNTs and NF surface and dried at ambient temperature without light. For stability, NF-CAT-GNP-MWCNTs-PGE was covered with a thin layer of $4 \mathrm{~mL}$ of $1 \% \mathrm{NF}$ solution. Similarly NF-CAT-PGE and NF-CAT-MWCNTs-PGE were prepared as mentioned above.

Figure 7. CVs of SWNTs-CS-CAT-GCE in PBS pH 7 at a scan rate of $0.1 \mathrm{~V} \mathrm{~s}^{-1}$ in the presence of (a) 0 , (b) 1 , and (c) $4 \mathrm{mM} \mathrm{H}_{2} \mathrm{O}_{2}$ (reproduced with permission from Jiang et al. J. Electroanal. Chem. 2008, 623, 181-186).

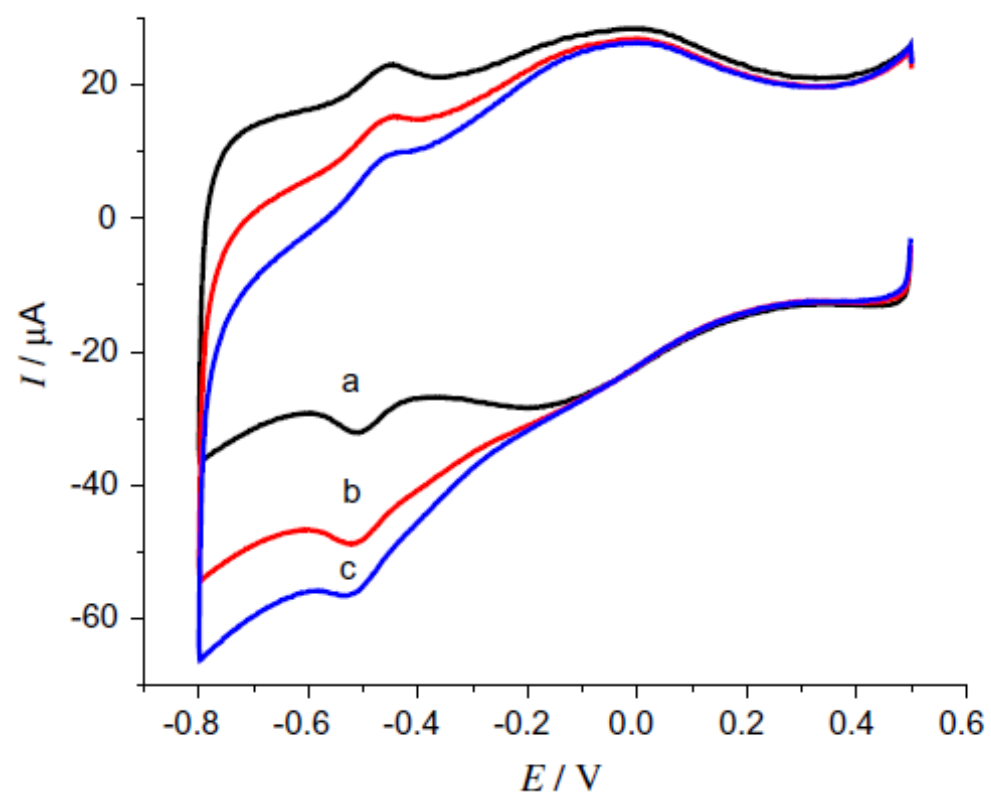

The effect of GNPs on microstructures of CAT was examined through UV-vis spectroscopy results. An intense band at $280 \mathrm{~nm}$ with similar site/shape was observed for both CAT solution and CAT-GNP mixture. This in turn confirms that CAT in the mixture retains its native structure without the loss of biological activity. CV studies explain that NF-CAT-GNP-MWCNTs-PGE displays a pair of welldefined and nearly reversible redox peak in 6.98 PBS (Figure 8c). The anodic peak potential (Epa), cathodic peak potential $(\mathrm{Epc})$ and formal potential $\left(\mathrm{E}^{0^{\prime}}\right)$ at NF-CAT-GNP-MWCNTs-PGE was observed to be $-0.461,-0.495 \mathrm{~V}$ and $-0.478 \mathrm{~V}$, respectively. From the slope of cathodic peak currents vs. scan rate, $\Gamma$ value of CAT was found to be about $2.4 \mathrm{nmol} \mathrm{cm}^{-2}$. Electrochemical impedance spectroscopy (EIS) results show that both GNP-PGE and MWCNTs-PGE exhibits two obvious semicircles with smaller diameter, which provides strong evidence that GNP and MWCNTs promoted the electron transfer between CAT and PGE. As reported by Zhang et al, the interaction between the amino groups of enzyme and GNPs greatly facilitates the electron transfer process [39]. The transfer coefficient $(\alpha)$ and $k_{\mathrm{s}}$ of CAT was observed to be 0.49 and $1.387 \mathrm{~s}^{-1}( \pm 0.1)$, respectively. This observed $k_{\mathrm{s}}$ value was relatively lower than that reported at nanomaterial-free matrices [20-22,24]. However, it 
was higher than CAT-SF films [21]. NF-CAT-GNP-MWCNTs-PGE also exhibits a high stability on storage. When stored at $-20^{\circ} \mathrm{C}$ for 20 days the reduction peak current decreased only to $8 \%$.

Figure 8. CVs of (a) NF-GNP-PGE, (b) NF-CAT-PGE, (c) NF-CAT-GNP-PGE (d) NFCAT-GNP-MWCNTs-PGE electrode in $0.1 \mathrm{M} \mathrm{pH} 6.98 \mathrm{PBS}$ at scan rate of $100 \mathrm{mV} \mathrm{s}^{-1}$ (reproduced with permission from Zhou et al. Anal. Lett. 2008, 41, 1832-1849).

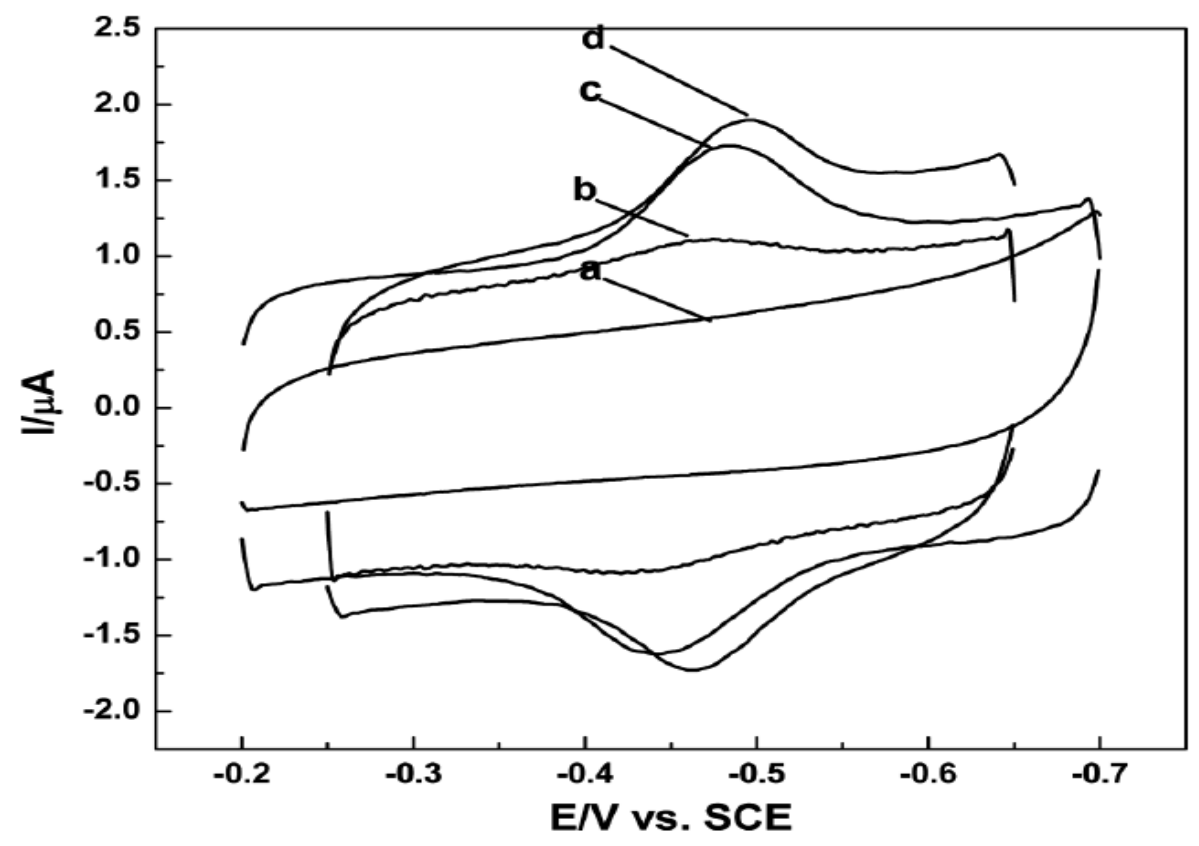

Further, the NF-CAT-GNP-MWCNTs-PGE exhibits an enhanced catalytic activity towards $\mathrm{H}_{2} \mathrm{O}_{2}$ and the catalytic current increased with increase in $\mathrm{H}_{2} \mathrm{O}_{2}$ concentration. The linear response of the modified electrode was 1-5 mM (See Table 1). The $K_{\mathrm{m}}$ value was observed to be $1.71 \mathrm{mM}( \pm 0.05)$, which in turn implies that the modified PGE exhibits higher affinity towards $\mathrm{H}_{2} \mathrm{O}_{2}$.

\subsection{CAT Immobilized on MWCNTs Incorporated Glassy Carbon Electrodes}

Salimi et al. successfully immobilized CAT on a MWCNTs modified GCE [40]. The detailed electrode modification procedure of MWCNTs-CAT modified GCE is illustrated as follows: prior to each experiments, 15 cycle scans were performed on a the clean GCE in the potential range of -2.0 to $+2.0 \mathrm{~V}$ vs. SCE in a solution of $1 \mathrm{M} \mathrm{H}_{2} \mathrm{SO}_{4}$ [41]. About $25 \mu \mathrm{L}$ of $0.4 \mathrm{mg} \mathrm{mL}^{-1}$ of acetone-MWCNTs solution was casted on the GCE and dried in air. In order to obtain a well defined stable CV, the resulting MWCNTs-GCE was dipped in $0.5 \mathrm{mM}$ of CAT in $0.1 \mathrm{M}$ of PBS solution and subjected to consecutive potential cyclic scans in the potential range of -1.0 to $+1.5 \mathrm{~V}$ (scan rate $100 \mathrm{mV} \mathrm{s}^{-1}$ ). Finally, the modified GCE was removed from CAT solution and washed with double distilled water and stored in buffer at $\mathrm{pH} 7$ at $4{ }^{\circ} \mathrm{C}$ before use.

The direct electrochemistry of CAT immobilized on MWCNTs modified GCE was investigated through $\mathrm{CV}$. A pair of well defined and nearly reversible redox peaks were observed at $-0.05 \mathrm{~V}$ in PBS 6.5 for MWCNTs-CAT-GCE. The formal potential $\mathrm{E}^{0^{\prime}}$ of MWCNTs-CAT-GCE was ultimately more positive than the other electrodes [42-44] and approximately between 350-400 mV. The surface 
coverage (I) value of CAT (24 $\mathrm{nmol} \mathrm{cm}$ ) confirms the existence of a CAT monolayer on the MWCNTs electrode surface. A slope value of $61 \mathrm{mV} \mathrm{pH}^{-1}$ obtained through $\mathrm{pH}$ studies shows that the redox reaction of CAT was single electron coupled single proton transportation process [45]. MWCNTs-CAT-GCE also possesses a good stability on storage. When stored at $4{ }^{\circ} \mathrm{C}$ for 10 days, it shows a similar catalytic response and the reduction peak currents decreased only to $3 \%$. The $\alpha$ and $k_{\mathrm{s}}$ values are 0.42 and $80 \mathrm{~s}^{-1}$, respectively. Thus, the $k_{\mathrm{s}}$ value observed at MWCNTs-CAT-GCE was comparatively higher than that reported at nanomaterial free matrices [15,20-22,24] and lower than that reported at nanomaterial modified matrices [36]. With the addition of $\mathrm{H}_{2} \mathrm{O}_{2}$, MWCNTs-CAT-GCE exhibits an obvious catalytic reduction peak at $-0.25 \mathrm{~V}$. The catalytic peak current increased linearly with increase in $\mathrm{H}_{2} \mathrm{O}_{2}$ concentration in the range of 0.01 to $1 \mathrm{mM}$. The correlation coefficient was 0.9889 and the detection limit was $50 \mu \mathrm{M}$ at a signal-to-noise ratio of 3 . Amperometric i-t measurements show that MWCNTs-CAT GCE shows steady state response to $\mathrm{H}_{2} \mathrm{O}_{2}$ at $-0.3 \mathrm{~V}$ for a linear concentration range 0.01 to $0.1 \mathrm{mM}$. The sensitivity was $3.3 \mathrm{nA} \mu \mathrm{M}^{-1} \mathrm{~cm}^{-2}$. The correlation coefficient was 0.9998 and the detection limit was $1 \mathrm{M}$, respectively (See Table 1). Moreover, MWCNTs-CAT-GCE exhibits greater affinity towards $\mathrm{H}_{2} \mathrm{O}_{2}$ which was obvious from the observed $K_{\mathrm{m}}$ value, $1.7 \mathrm{mM}$.

Zhou and co-workers also succeeded in immobilizing CAT onto MWCNTs modified GCEs. They investigated the direct electrochemistry of CAT in $0.1 \mathrm{M}$ tris(hydroxymethyl)aminomethane (Tris)$\mathrm{HCl}$ buffer solution [46]. Interestingly, they reported the effect of $\mathrm{La}^{3+}$ ions on the electrocatalytic activity of CAT. Their results demonstrate that the electrochemical reaction of the immobilized CAT was promoted by low concentration of $\mathrm{La}^{3+}(0.001 \mathrm{mM})$ and inhibited by the high concentration $(0.01$ $\mathrm{mM}$ ) of $\mathrm{La}^{3+}$. This might be due to the reason that low concentration of $\mathrm{La}^{3+}$ increases the non planarity and the exposure extent of CAT heme group and vise versa. Moreover, the CAT modified electrode retains its catalytic activity and exhibits a good response to $\mathrm{H}_{2} \mathrm{O}_{2}$ concentration in the concentration range 1 to $4.8 \mathrm{mM}$ respectively. The $k_{\mathrm{s}}$ value was observed to be $1.07 \mathrm{~s}^{-1}$. This was much lower than that reported at some nanomaterial modified matrices [36,40] and nanomaterial free matrices [20,22,24].

Recently we reported the direct electrochemistry of CAT on a NF dispersed MWCNTs modified GCE both in the presence and absence of DDAB [47]. We revealed through our studies that the presence of DDAB in the MWCNTs-NF-CAT film produced a $48 \%$ enhancement in the surface coverage concentration of CAT $\left(\mathrm{Fe}^{\mathrm{III} / \mathrm{II}}\right)$ and $66 \%$ enhancement in $k_{\mathrm{s}}$ value, whereas the CAT stability increased by $57 \%$. We also reported a maximum $k_{\mathrm{s}}$ value of $11 \mathrm{~s}^{-1}$ at MWCNTs-NF-(DDAB/CAT) film modified GCE. Thus the $k_{\mathrm{s}}$ value observed at MWCNTs-NF-(DDAB/CAT) film modified GCE was comparatively higher than that observed at nanomaterial free matrices [15,21] and nanomaterial modified matrices [36,46]. Moreover, the sensitivity values of MWCNTs-NF-(DDAB/CAT) film for $\mathrm{H}_{2} \mathrm{O}_{2}$ reduction was calculated using $\mathrm{CV}$ and i-t curve measurements and it was about 35.62 and $101.74 \mu \mathrm{A} \mathrm{mM} \mathrm{m}^{-1} \mathrm{~cm}^{2}$ respectively (See Table 1). The possible interactions between MWCNTs-NF, DDAB and CAT at MWCNTs-NF-(DDAB/CAT) film on GCE have been given in Figure 9. 
Figure 9. The possible interaction between MWCNTs, NF, DDAB and CAT in MWCNTsNF-(DDAB/CAT) film modified electrodes. (Reproduced with permission from Prakash et al. Talanta, doi:10.1016/j.talanta.2009.02.033, article in press).

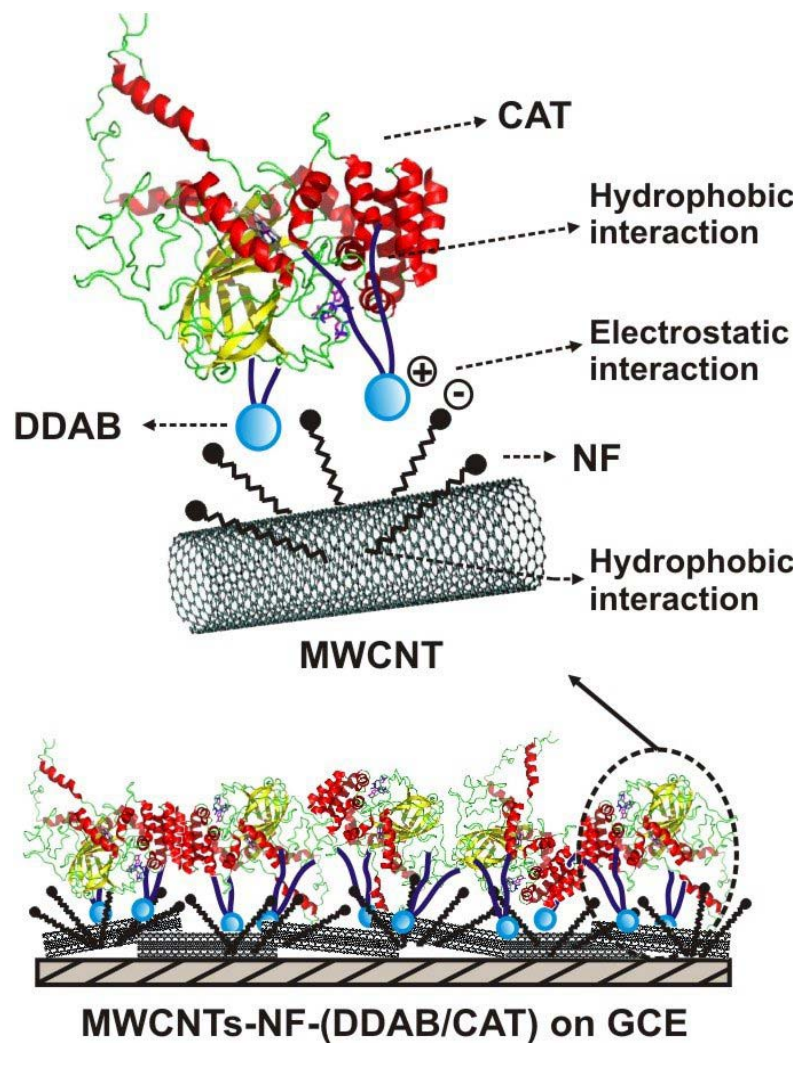

\subsection{Covalent Immobilization of CAT on Conductive Composite Nanofiber Meshes}

Wang et al. co-immobilized CAT on a neat poly(acrylonitrile-co-acrylic acid) (PANCAA) nanofiber mesh using 1-ethyl-3-(3-dimethylaminopropyl) carbodiimide hydrochloride (EDC) and $N$ hydroxy-succinimide (NHS) [48]. They also immobilized CAT on PANCAA and MWCNTs incorporated composite matrices. Their detailed enzyme immobilization procedure was described here. About $2 \mathrm{mg}$ of the pretreated PANCAA/MWCNTs nanofiber mesh was soaked into $50 \mathrm{mM}$ EDS/NHS $(1: 1)$ PBS and shaken gently for $6 \mathrm{~h}$ at room temp and thus activated. This activated nanofiber mesh was later mixed with CAT $\left(0.10 \mathrm{mg} \mathrm{mL}^{-1} \mathrm{PBS}\right)$ at room temp for a suitable time. Their results show that the activity of CAT on composite nanofiber matrix was $42 \%$ higher than that of neat PANCAA nanofiber matrices. Furthermore, the electrical conductivity and viscosity of PANCAA/MWCNTs were superior to that of PANCAA alone. This may be due to the interaction between -COOH groups of etched MWCNTs and DMF and -COOH groups of PANCAA through hydrogen bond. The $K_{\mathrm{m}}$ value for free CAT, CAT/ PANCAA and CAT/PANCAA/MWCNTs composite nanofiber mesh were observed to be about 34.07, 77.9 and $58.14 \mathrm{mM}$, respectively. The reasons for the higher $K_{\mathrm{m}}$ value of CAT at PANCAA and PANCAA/MWCNTs matrix might be due to conformational changes of CAT and the formation of a substrate-CAT complex. Furthermore, the increased limitation in diffusion also lessens the accessibility of the substrate to the active sites of immobilized CAT and thus promotes the $K_{\mathrm{m}}$ value. 
Similarly, Wan et al. used poly(acrylonitrile-co- $N$-vinyl-2-pyrrolidone) (PANCNVP) and polyacrylonitrile (PAN) electrospun nanofibrous membranes with and without MWCNTs for the efficient immobilization of CAT [49]. The enzyme immobilization procedure involves two steps as explained in Figure 10. The first step involves the alkali treatment of the electrospun nanofibrous membranes, which results in the generation of - $\mathrm{COOH}$ groups. The second step was the activation step and it involves the treatment of nanofibrous membranes with EDC/NHS. The FESEM and TEM results confirm that presence of MWCNTs in the nanofibers increased the surface area, number of carboxylic groups and surface roughness. Further studies show that the presence of MWCNTs in the nanofibrous membranes increased the amount of immobilized CAT. The maximum amount of CAT was immobilized on PAN/MWCNTs $\left(29.81 \pm 3.76 \mathrm{mg} \mathrm{g}^{-1}\right.$ fibres) and PANCNVP/MWCNTs $(25.77 \pm 4.10$ $\mathrm{mg} \mathrm{g}^{-1}$ fibres) composite nanofibrous membranes, respectively. MWCNTs presence increased the activity retention and electrical conductivity of the nanofibres. Thus, CAT immobilized at PANCNVP/MWCNTs membrane possesses maximum activity retention (48.7 \%), whereas PAN/MWCNTs possess a little lower activity retention (45.3\%). Compared to free CAT, nanofibrous membrane immobilized CAT possesses lower, maximum reaction rates (Vmax) and higher $K_{\mathrm{m}}$ values. Their detailed stability studies also elucidate that nanofibrous membrane immobilized CAT possess improved stability. Further the immobilized CAT remains more biocompatible especially in the presence of MWCNTs. Thus among various nanofibrous membranes, MWCNTs containing nanofibrous membranes are most suited for CAT immobilization.

Figure 10. The two steps involved in the CAT immobilization are (Step 1) Activation of nanofibrous membrane through alkali treatment and (Step 2) Enzyme immobilization using EDC/NHS (reproduced with permission from Wan et al. Enzyme Microb. Technol. 2008, 42, 332-339).

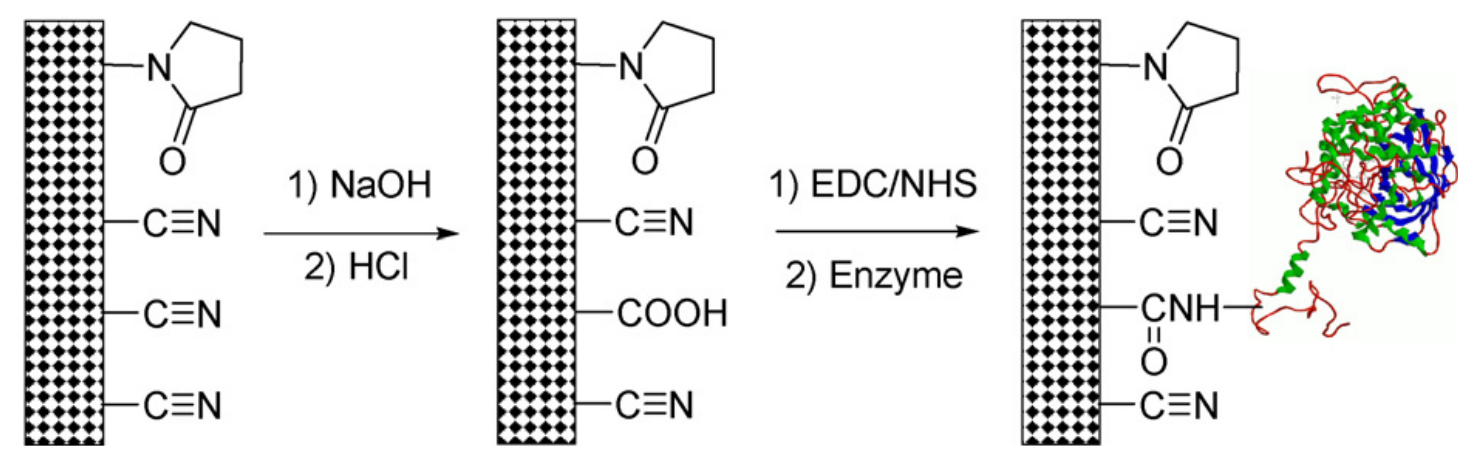

In an alternative approach, Wan and co-workers covalently immobilized CAT onto electrospun nanofibres $(\mathrm{dia}=180 \mathrm{~nm})$ of acrylonitrile-based copolymers containing porphyrin pendants, either in the presence or absence of MWCNTs [50]. The terpolymer, PANAACoPP was prepared from acrylonitrile, acrylic acid and metalloporphyrin with $\mathrm{Co}^{2+}$. Then nanofibers were fabricated from this terpolymer using an electrospining technique. The field emission scanning electron microscopy (FESEM) images obtained for various nanofibers both in the presence and absence of MWCNTs are shown in Figure 11. They clearly display that MWCNTs present in PAN/MWCNT and PANAACoPP/MWCNT nanofibres increased the roughness of the nanofibres. Moreover, due to the 
lower surface tension of the polymer solution, MWCNTs were mostly covered with thin polymer film and thus not much exposed to air.

Figure 11. FESEM images of the electrospun nanofibers: (a) PAN (154 $\pm 30 \mathrm{~nm}$ ); (b) PANAACoPP (180 $\pm 30 \mathrm{~nm}$ ); (c) PAN/CNT (180 $\pm 34 \mathrm{~nm})$; (d) PANAACoPP/CNT (165 \pm 37 nm) (reproduced with permission from Wan et al. J. Phys. Chem. C 2007, 111, 1409114097).
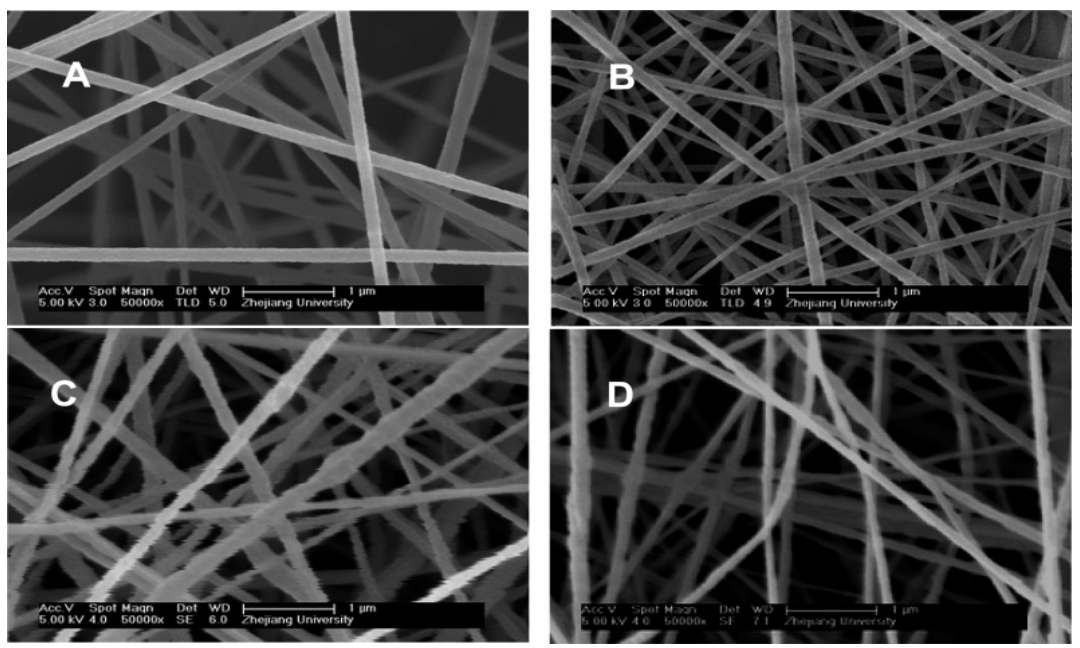

Their detailed studies show that the nanofibers with MWCNTs contain greater amounts of CAT than without MWCNTs. For instance, in the absence of MWCNTs, one gram of PAN fibers contains only $24.45 \pm 2.33 \mathrm{mg}$ CAT, whereas they contain $29.81 \pm 3.76 \mathrm{mg}$ CAT in the presence of MWCNTs. Similarly, one gram of PANAACoPP nanofibres has only $18.93 \pm 4.03 \mathrm{mg}$ CAT, whereas PANAACoPP/MWCNTs contain more CAT $(22.81 \pm 4.22 \mathrm{mg})$. The specific activity and retention activity also increased in the presence of MWCNTs, however, the $K \mathrm{~m}$ value decreased and $\mathrm{V}_{\max }$ increased in the presence of MWCNTs. This clearly shows that blending of nanofibres with MWCNTs has significantly increased the characteristics of CAT in the nanofiber matrices. Their further studies indicate that both the introduction of porphyrin pendants and MWCNTs obviously improve the activity and stabilities of the immobilized CAT. The reason for the improvement in activity and stability might be due to the enhanced electron transfer between the immobilized CAT molecules and the ability of both porphyrin pendants and MWCNTs to retain the active conformation of the CAT.

\subsection{CAT Immobilized on Nickel Oxide Nanoparticles Modified Glassy Carbon Electrodes}

Salimi and co-workers reported the direct electrochemistry of CAT on nickel oxide (NiO) nanoparticles modified GCE [51]. The NiO nanoparticles modified GC and indium tin oxide (ITO) electrodes were prepared as follows: initially $\mathrm{Ni}(-1.0 \mathrm{~V}, 5 \mathrm{~min}$ deposition time) was electrodeposited on a GCE using $1 \mathrm{mM}$ nickel nitrate $\mathrm{pH} 4$ acetate buffer solution. Then they repetitively cycled (30 scans) from 1.5 to $-1.0 \mathrm{~V}$ at scan rate $100 \mathrm{mV} \mathrm{s}^{-1}$ in fresh PBS solution for electrodissolution and passivation of $\mathrm{NiO}$ layer. They determined the effective area of the modified electrode as $0.033 \mathrm{~cm}^{2}$ from $\mathrm{CVs}$ of $10 \mathrm{mM} \mathrm{K}_{4}\left[\mathrm{Fe}(\mathrm{CN})_{6}\right]$ in buffer solution at $\mathrm{pH}$ 7. They employed the same procedure for electrodeposition of $\mathrm{NiO}$ nanoparticles on ITO. Figure 12 shows the scanning electron microscopy 
(SEM) image of $\mathrm{NiO}$ film electrochemically deposited at GCE. This shows that the particle size of $\mathrm{NiO}$ varied from $100 \mathrm{~nm}$ to $700 \mathrm{~nm}$. The larger particles are shown at the bottom right. Similarly, the immobilization of CAT on GCE and ITO modified with nano-scale islands of NiO was carried out using the following procedures. $\mathrm{CV}$ was used for immobilization of CAT on $\mathrm{NiO}$ nanoparticles with a one step method.

After the deposition of metallic Ni on GCE, the electrode was immersed in fresh PBS pH 7 solution containing $5 \mathrm{mg} \mathrm{mL}^{-1} \mathrm{CAT}$ and the potential was repetitively cycled (30 scans) from +1 to $-0.5 \mathrm{~V}$ at scan rate $100 \mathrm{mV} \mathrm{s}^{-1}$ for electrodissolution and passivation of $\mathrm{NiO}$ layer and immobilization of CAT. They used the same procedure to immobilize CAT and $\mathrm{NiO}$ on an ITO electrode. The CAT films on $\mathrm{NiO}$ exhibits a pair of well defined, stable and nearly reversible CV peaks at about $-0.05 \mathrm{~V}$ vs. SCE at $\mathrm{pH}$ 7. $\mathrm{E}^{0}$ of $\mathrm{CAT}$ in $\mathrm{NiO}$ film linearly varied in the range $1-12$ with slope of $58.426 \mathrm{mV}^{-1}$, indicating that the electron transfer is accompanied by single proton transportation. Moreover, $\alpha$ and $k_{\mathrm{s}}$ values for NiO-CAT-GCE were observed to be 0.45 and $3.7 \mathrm{~s}^{-1}( \pm 0.1)$, respectively. The reason for more facile electron transfer process at NiO-CAT-GCE was due to the larger surface area and more porous structure of $\mathrm{NiO}$ nanoparticles which helps for the better entrapment of CAT. Further, NiO acts as a molecular wire and enhances the direct electron transfer of CAT. Their detailed studies illustrate that the chemical stability of $\mathrm{NiO}$ film and the interaction between CAT and NiO NPs have enhanced the overall stability of modified electrode. NiO-CAT GCE on 10 days storage $\left(4{ }^{\circ} \mathrm{C}\right)$ showed no shift in $\mathrm{CV}$ potentials and the reduction peak currents decreased only to $2 \%$.

Figure 12. SEM image of the electrodeposited $\mathrm{NiO}$ on GCE, scale bare $20 \mu \mathrm{m}$. Inset is the SEM image with higher magnification for the same sample, scale bar is $2 \mu \mathrm{m}$ (reproduced with permission from Salimi et al. Biophys. Chem. 2007, 125, 540-548).

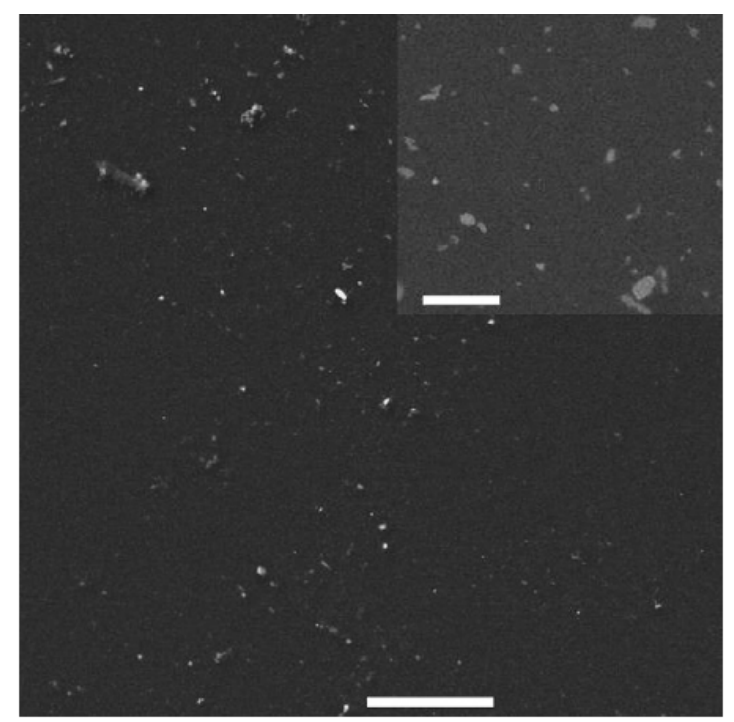

The CAT embedded in $\mathrm{NiO}$ nanoparticles shows excellent electrocatalytic activity towards $\mathrm{H}_{2} \mathrm{O}_{2}$ reduction with a linear range from 0.1 to $5.0 \mathrm{mM}$. The detection limit was $10 \mu \mathrm{M}$ with a signal to noise ratio of 3 . NiO-CAT modified GCE also exhibits a fast amperometric response within $2 \mathrm{~s}$ to $\mathrm{H}_{2} \mathrm{O}_{2}$ in the linear concentration range $0.001-1.0 \mathrm{mM}$. The sensitivity was observed to be $15.9 \mathrm{nA}$ $\mu \mathrm{M}^{-1}$ and the correlation coefficient was 0.9988 respectively. The detection limit was found to be 0.60 
$\mu \mathrm{M}$. Thus, NiO-CAT modified GCE possess an excellent stability, long life and good reproducibility towards $\mathrm{H}_{2} \mathrm{O}_{2}$ determination. The apparent $K_{\mathrm{m}}$ value was $0.96 \mathrm{mM}( \pm 0.05)$, which shows the excellent catalytic activity of CAT incorporated $\mathrm{NiO}$ films towards $\mathrm{H}_{2} \mathrm{O}_{2}$. Moreover, exceptional electrochemical reversibility of redox couple, high stability, technical simplicity, lack of need for mediators and short preparation times are advantages of this NiO-CAT modified electrode.

\section{Benefits of Nanomaterial Matrices above Nanomaterial Free Matrices for Efficient CAT Immobilization towards the Development of CAT Based Electrochemical Sensors}

Miscellaneous CAT immobilization techniques, detailed electrode fabrication procedures along with various electrochemical and morphological characterizations both in the absence and presence of nanomaterials have been presented in Sections 2 and 3. The electrochemical parameters obtained through $\mathrm{CV}$ and i-t curve measurements for various nanomaterial modified electrodes were compared with that of nanomaterial free electrodes and given in Table 1. It was obvious from this Table that excellent electrocatalytic activity of CAT with very high sentivity and low detection limit was more pronounced in nanomaterial matrices rather than nanomaterial free matrices. In addition, the results discussed in Sections 2 and 3 clearly show that nanomaterial modified matrices are superior to nanomaterial free matrices in several aspects. Being extremely miniaturized in size and having large surface areas, nanomaterials are an excellent choice for CAT immobilization. CAT immobilized on those nanomaterial matrices remains extremely compatible and undergoes facile electron transfer processes. With excellent mechanical strength and exceptional conductivity, SWCNTs are more appropriate for CAT immobilization. As discussed in Sections 3.1 and 3.2, the presence of SWCNTs greatly facilitates the electron transfer process. Moreover, the $k_{\mathrm{s}}$ value for CAT at SWCNT-CS matrix was observed to be $118 \mathrm{~s}^{-1}$. It was comparatively higher than any of the nanomaterial modified and nanomaterial-free electrodes discussed before. Further, the detection limit, linear range and sentivity calculated at CAT-SWCNTs-CS modified electrode are given in Table 1. This in turn confirms the good catalytic ability of this SWCNTs modified electrode. Other than SWCNTs, the stability and activity of CAT greatly improved at MWCNTs matrices. This might be due to the biocompatible microenvironment of MWCNTs, which facilitates the immobilized CAT to retain its activity. Moreover, in the presence of MWCNTs the surface area and roughness largely increased. As described in Section 3.5, the activity retention and electrical conductivity extensively improved in the presence of MWCNTs. Moreover, the large surface area and porous nature of MWCNTs surfaces assists in the entrapment of more CAT. The electron transfer also becomes facile at MWCNTs matrices. It was obvious that the maximum peak current and lesser peak separation of CAT redox couples was observed at MWCNTs matrices. Furthermore, the electrocatalytic activity of CAT also considerably enhanced at MWCNTs matrices (see Table 1). MWCNTs-CAT modified GCE exhibits good catalytic activity towards $\mathrm{H}_{2} \mathrm{O}_{2}$. The lowest detection limit was observed to be $1 \mu \mathrm{M} \mathrm{H}_{2} \mathrm{O}_{2}$ and the sensitivity was $3.3 \mu \mathrm{A} \mathrm{mM} \mathrm{m}^{-1} \mathrm{~cm}^{-2}$, respectively. Other than, MWCNTs, NiO nanoparticles modified GCE also possess promising catalytic activity. The NiO-CAT-GCE exhibits a very high sensitivity of $15.9 \mu \mathrm{A}$ $\mathrm{mM}^{-1} \mathrm{~cm}^{-2}$ with $0.6 \mu \mathrm{M} \mathrm{H}_{2} \mathrm{O}_{2}$ as lowest detection limit. The linear range of $\mathrm{H}_{2} \mathrm{O}_{2}$ concentration was about 0.001-1.0 mM respectively. Thus among various nanomaterials, CNTs and CNT incorporated 
matrices are excellent choices for better CAT immobilization and for the achievement of facile direct electrochemistry.

Table 1. The electrochemical parameters of various CAT-modified electrodes calculated through CV and amperometric i-t studies.

\begin{tabular}{|c|c|c|c|c|c|c|}
\hline Modified Electrode & Techniques & $\begin{array}{c}E_{p a}^{a}(o r) \\
E_{p c}^{b} \\
(V)\end{array}$ & $\begin{array}{c}\begin{array}{c}\text { Linear } \\
\text { range } \\
(\mathrm{mM})\end{array} \\
\end{array}$ & $\begin{array}{l}\text { Sensitivity ( } \mu \mathrm{A} \\
\left.\mathrm{mM}^{-1} \mathbf{c m}^{-2}\right)\end{array}$ & $\begin{array}{c}\text { Detection } \\
\text { limit } \\
(\mu \mathrm{M}) \\
\end{array}$ & Ref \\
\hline CAT-PAM & $\mathrm{CV}$ & $-0.5^{\mathrm{b}}$ & $0.4-0.8$ & - & - & {$[18]$} \\
\hline CAT-MC & $\mathrm{CV}$ & $-0.4^{\mathrm{b}}$ & $0.02-0.12$ & - & - & [19] \\
\hline CAT-SF & $i-t$ & $-0.2^{\mathrm{b}}$ & $\begin{array}{l}0.003- \\
0.158\end{array}$ & - & - & {$[21]$} \\
\hline CAT-PNM & $i-t$ & $-0.25^{\mathrm{b}}$ & $\begin{array}{l}0.002- \\
0.035\end{array}$ & - & - & {$[22]$} \\
\hline $\begin{array}{c}\mathrm{CAT} / \text { cysteine/Si sol- } \\
\text { gel }\end{array}$ & $i-t$ & $0.1^{\mathrm{b}}$ & $0.001-0.03$ & - & 0.4 & {$[23]$} \\
\hline CAT-agarose & $\mathrm{CV}$ & $-0.24^{\mathrm{b}}$ & $\begin{array}{l}0.001- \\
0.818\end{array}$ & - & - & {$[24]$} \\
\hline CAT-SWCNTs & $\mathrm{CV}$ & $-0.4^{\mathrm{a}}$ & $0.7-1.1$ & - & 4.0 & [29] \\
\hline CAT-SWCNTs-CS & $\mathrm{CV}$ & $-0.52^{\mathrm{b}}$ & $5-50$ & 6.32 & 2.5 & {$[35]$} \\
\hline $\begin{array}{c}\text { NF-MWCNTs- } \\
\text { CAT-GNP }\end{array}$ & $\mathrm{CV}$ & $-0.29^{\mathrm{a}}$ & $1-5$ & - & - & {$[36]$} \\
\hline CAT-MWCNTs & $i-t$ & $-0.3^{b}$ & $0.01-0.1$ & 3.3 & 1.0 & {$[40]$} \\
\hline CAT-MWCNTs & $\mathrm{CV}$ & $-0.56^{\mathrm{b}}$ & $1.0-4.8$ & - & - & {$[46]$} \\
\hline $\begin{array}{l}\text { MWCNTs-NF- } \\
\text { (DDAB/CAT) }\end{array}$ & $\mathrm{CV}$ & $-0.38^{b}$ & $0.5-1.2$ & 35.62 & 150 & {$[47]$} \\
\hline CAT-NiO & $\mathrm{i}-\mathrm{t}$ & $-0.3^{\mathrm{b}}$ & $0.001-1.0$ & 15.9 & 0.60 & {$[51]$} \\
\hline
\end{tabular}

${ }^{\mathrm{a}}$ Anodic peak potential (Epa)

${ }^{\mathrm{b}}$ cathodic peak potential (Epc)

\section{Conclusions}

The versatile approaches practiced in the immobilization of CAT onto various matrices for the achievement of direct electron transfer have been reviewed. For this purpose CAT has been immobilized on various modified electrode surfaces both in the presence and absence of nanomaterials. All the CAT modified films were electrochemically characterized and their catalytic efficiency towards $\mathrm{H}_{2} \mathrm{O}_{2}$ was also investigated. The results illustrate that CAT incorporated 
nanomaterial matrices show outstanding characteristics like facile electron transfer, high sensitivity, low detection limit and excellent stability. Thus they are superior to CAT incorporated nanomaterial free matrices in several aspects. Although some nanomaterial free matrices promoted the direct electrochemistry of CAT, the majority of them slow down the electron transfer process. This might be due to the lesser contact noticed between CAT and those nanomaterial free matrices. On the other hand, most of the nanomaterials acted as nanowires and helped for the achievement of better contact between CAT and the electrode surface. This ultimately facilitated the electron transfer process. In the midst of various nanomaterial matrices, more fascinating direct electron transfer process was observed at CNTs modified matrices. Moreover, with large surface area and numerous pores on their surfaces, CNTs matrices have excellent ability to trap large amount of CAT molecules. CNTs incorporated CAT also exhibits excellent catalytic activity towards $\mathrm{H}_{2} \mathrm{O}_{2}$ and ultimately helps for the CAT based electrochemical sensors development. The future aspects of CAT based sensors depend on the development of novel nanomaterials with some advantageous properties. This perhaps helps for the better immobilization and significant enhancement in the direct electrochemistry of CAT and other CAT based redox enzymes and protein direct electrochemistry.

\section{Acknowledgements}

National Taipei University of Technology assisted in meeting the publication costs of this article.

\section{References}

1. Armstrong, F.A.; Wilson, G.S. Recent developments in faradaic bioelectrochemistry. Electrochim. Acta 2000, 45, 2623-2645.

2. Hill, H.A.O.; Hunt, N.I. Direct and indirect electrochemical investigations of metalloenzymes. Methods Enzymol. 1993, 227, 501-522.

3. Bond, A.M. Chemical and electrochemical approaches to the investigation of redox reactions of simple electron transfer metalloproteins. Inorg. Chim. Acta 1994, 226, 293-340.

4. Ghindilis, A.L.; Atanasov, P.; Wilkins, E. Enzyme-catalyzed direct electron transfer: Fundamentals and Analytical Applications. Electroanalysis 1997, 9, 661-674.

5. Ferapontova, E.E.; Ruzgas, T.; Gorton, L. Direct electron transfer of heme and molybdopterin cofactor-containing chicken liver sulfite oxidase on alkanethiol-modified gold electrodes. Anal. Chem. 2003, 75, 4841-4850.

6. Gorton, L.; Lindgren, A.; Larsson, T.; Munteanu, F. D.; Ruzgas, T.; Gazaryan, I. Direct electron transfer between heme-containing enzymes and electrodes as basis for third generation biosensors. Anal. Chim. Acta 1999, 400, 91-108.

7. Yeh, P.; Kuwana, T. Reversible electrode reaction of cytochrome C. Chem. Lett. 1977, 6, 11451148 .

8. Eddowes, M. J.; Hill, H.A.0. Novel method for the investigation of the electrochemistry of metalloproteins : cytochrome C. J. Chem. Soc., Chem. Commun. 1977, 771-772.

9. Wollenberger, U.; Spricigo, R.; Leimkühler, S.; Schröder, K. Protein electrodes with direct electrochemical communication. Adv. Biochem. Engi. Biotechnol. 2008, 109, 19-64. 
10. Nicholls, P.; Schonbaum, G.R.; Boyer, I.; Lardy, P.D.; Myrback, H. The Enzymes; Academic Press: Orlando 1963; Volume 8, pp. 158-159.

11. Buleandra, M.; Radu, G.L; Tanase, I. Redox protein electroanalysis: metalloproteins. Roum. Biotechnol. Lett. 2000, 5, 423-438.

12. Lai, M.E.; Bergel, A. Direct electrochemistry of catalase on glassy carbon electrodes. Bioelectrochemistry 2002, 55, 157-160.

13. Caruso, F.; Trau, D.; Mohwald, H.; Renneberg, R. Enzyme encapsulation in layer-by-layer engineered polymer multilayer capsules. Langmuir 2000, 16, 1485-1488.

14. Yu, A.; Caruso, F. Thin films of polyelectrolyte-encapsulated catalase microcrystals for biosensing. Anal. Chem. 2003, 75, 3031-3037.

15. Chen, X.; Xie, H.; Kong, J.; Deng, J. Characterization for didodecyldimethylammonium bromide liquid crystal film entrapping catalase with enhanced direct electron transfer rate. Biosens. Bioelectron. 2001, 16, 115-120.

16. Gebicka, L.; Gebicki, J.L. Interaction of sodium bis (2-ethylhexyl) sulfosuccinate (AOT) with catalase and horseradish peroxidase in an aqueous solution and in the reverse micelles of AOT/nheptane. Biochem. Mol. Biol. Int. 1998, 45, 805-811.

17. Huang, H.; Hu, N.; Zeng, Y.; Zhou, G. Electrochemistry and electrocatalysis with heme proteins in chitosan biopolymer films. Anal. Biochem. 2002, 308, 141-151.

18. Lu, H.Y.; Li, Z.; Hu, N.F. Direct voltammetry and electrocatalytic properties of catalase incorporated in polyacrylamide hydrogel films. Biophys. Chem. 2003, 104, 623-632.

19. Li, Y.M.; Chen, X.T.; Li, J.; Liu, H.H.; Direct voltammetry and catalysis of hemoenzymes in methyl cellulose film. Electrochim. Acta 2004, 49, 3195-3200.

20. Li, M.; He, P.; Zhang, Y.; Hu, N. An electrochemical investigation of hemoglobin and catalase incorporated in collagen films. Biochim. Biophys. Acta 2005, 1749, 43-51.

21. Wu, Y.; Shen, Q.; Hu, S. Direct electrochemistry and electrocatalysis of heme-proteins in regenerated silk fibroin film. Anal. Chim. Acta 2006, 558, 179-186.

22. Sun, Y.X.; Wang, S.F. Direct electrochemistry and electrocatalytic characteristic of heme proteins immobilized in a new sol-gel polymer film. Bioelectrochemistry 2007, 71, 172-179.

23. Di, J.; Zhang M.; Yao, K.; Bi, S. Direct voltammetry of catalase immobilized on silica sol-gel and cysteine modified gold electrode and its application. Biosens. Bioelectron. 2006, 22, 247-252.

24. Wang, S.F.; Chen, T.; Zhang, Z.L.; Pang, D.W.; Wong, K.L. Effects of hydrophilic roomtemperature ionic liquid 1-butyl-3-methylimidazolium tetrafluoroborate on direct electrochemistry and bioelectrocatalysis of heme proteins entrapped in agarose hydrogel films. Electrochem. Commun. 2007, 9, 1709-1714.

25. Shen, L.; Hu, N. Heme protein films with polyamidoamine dendrimer: direct electrochemistry and electrocatalysis. BBA-Bioenergetics 2004, 1608, 23-33.

26. Salimi, A.; Miranzadeh, L.; Hallaj, R.; Mamkhezri, H. Picomolar detection of hydrogen peroxide at glassy carbon electrode modified with $\mathrm{NAD}^{+}$and single walled carbon nanotubes. Electroanal. 2008, 20, 1760-1768.

27. Shi, L.; Liu, X.; Niu, W.; Li, H.; Han, S.; Chen, J.; Xu, G. Hydrogen peroxide biosensor based on direct electrochemistry of soybean peroxidase immobilized on single-walled carbon nanohorn modified electrode. Biosens. Bioelectron. 2009, 24, 1159-1163. 
28. Cosnier, S.; Ionescu, R.E.; Holzinger, M. Aqueous dispersions of SWCNTs using pyrrolic surfactants for the electro-generation of homogeneous nanotube composites. Application to the design of an amperometric biosensor. J. Mater. Chem. 2008, 18, 5129-5133.

29. Wang, L.; Wang, J.; Zhou, F. Direct electrochemistry of catalase at a gold electrode modified with single-wall carbon nanotubes. Electroanal, 2004, 16, 627-632.

30. Miao, Y.; Chia, L.S.; Goh, N.K.; Tan, S.N. Amperometric glucose biosensor based on immobilization of glucose oxidase in chitosan matrix cross-linked with glutaraldehyde. Electroanal 2001, 13, 347-349.

31. Okuma, H.; Watanabe, E. Flow system for fish freshness determination based on double multi enzyme reactor electrodes. Biosens. Bioelectron. 2002, 17, 367-372.

32. Hikima, S.; Kakizaki, T.; Taga, M.; Hasebe, K. Enzyme sensor for L-lactate with a chitosan mercury film electrode. J. Anal. Chem. 1993, 345, 607-609.

33. Chen, L.; Gorski, W. Bioinorganic composites for enzyme electrodes. Anal. Chem. 2001, 73, 2862-2868.

34. Jiang, H.; Du, C.; Zou, Z.; Li, X.; Akins, D.; Yang, H. A biosensing platform based on horseradish peroxidase immobilized onto chitosan-wrapped single-walled carbon nanotubes. $J$. Solid State Electrochem. 2009, 13, 791-798.

35. Jiang, H.J.; Yang, H.; Akins, D.L. Direct electrochemistry and electrocatalysis of catalase immobilized on a SWNT-nanocomposite film. J. Electroanal. Chem. 2008, 623, 181-186.

36. Zhou, B.; Wang, J.; Gao, X.; Tian, Y. Attachment of nanoparticles to pyrolytic graphite electrode and its application for the direct electrochemistry and electrocatalytic behavior of catalase. Anal. Lett. 2008, 41, 1832-1849.

37. Frens, G.; Controlled nucleation for the regulation of the particle size in monodisperse gold suspensions. Nat. Phys. Sci. 1973, 241, 20-22.

38. Chattopadhyay, D.; Galeska, I.; Papadimitrakopoulos, F. Metal-assisted organization of shortened carbon nanotubes in monolayer and multilayer forest assemblies. J. Am. Chem. Soc. 2001, 123, 9451-9452.

39. Zhang, B.; Zhang, Z.; Wang, B.; Yan, J.; Li, J.; Cai, S.M. Preparation of gold nano-arraied electrode on silicon substrate and its electrochemical properties: Probe into biosensor based on electroluminescence of porous silicon. Acta Chimi. Sin. 2001, 59, 1932-1936.

40. Salimi, A.; Noorbakhsh, A.; Ghadermarz, M. Direct electrochemistry and electrocatalytic activity of catalase incorporated onto multiwall carbon nanotubes-modified glassy carbon electrode. Anal. Biochem. 2005, 344, 16-24.

41. Zhao, G.C.; Zhang, L.; Wei, X.W.; Yang, Z.S. Myoglobin on multi-walled carbon nanotubes modified electrode: direct electrochemistry and electrocatalysis. Electrochem. Commun. 2003, 5, 825-829.

42. Lu, H.; Li, Z.; Hu, N. Direct voltammetry and electrocatalytic properties of catalase incorporated in polyacrylamide hydrogel films. Biophys. Chem. 2003, 104, 623-632.

43. Huang, H.; Hu, N.; Zeng, Y.; Zhou, G. Electrochemistry and electrocatalysis with heme proteins in chitosan biopolymer films. Anal. Biochem, 2002, 308, 141-151. 
44. Zhang, Z.; Chouchane, S.; Magiliozzo, R.S.; Rusling, J.F. Direct voltammetry and catalysis with mycobacterium tuberculosis catalase-peroxidase, peroxidases, and catalase in lipid films. Anal. Chem. 2002, 74, 163-170.

45. Bond, A.M. Modern polarographic methods in analytical chemistry; Marcel Dekker: New York, 1980.

46. Zhou, H.; Lu, T.H.; Shi, H.X.; Dai, Z.H.; Huang, X.H. Direct electrochemistry and electrocatalysis of catalase immobilized on multi-wall carbon nanotubes modified glassy carbon electrode and its application. J. electroanal. Chem. 2008, 612, 173-178.

47. Prakash, P.A.; Yogeswaran, U.; Chen, S.M. Direct electrochemistry of catalase at multiwalled carbon nanotubes - nafion in presence of needle shaped DDAB for $\mathrm{H}_{2} \mathrm{O}_{2}$ sensor. Talanta doi:10.1016/j.talanta.2009.02.033. (in press)

48. Wang, Z.G.; Ke, B.B.; Xu, Z.K. Covalent immobilization of redox enzyme on electrospun nonwoven poly(acrylonitrile-co-acrylic acid) nanofiber mesh filled with carbon nanotubes: a comprehensive study. Biotechnol. Bioeng. 2007, 97, 708-720.

49. Wan, L.S.; Ke, B.B.; Xu, Z.K. Electrospun nanofibrous membranes filled with carbon nanotubes for redox enzyme immobilization. Enzyme Microb. Technol. 2008, 42, 332-339.

50. Wan, L.S.; Ke, B.B.; Wu, J.; Xu, Z.K. Catalase immobilization on electrospun nanofibers: effects of porphyrin pendants and carbon nanotubes. J. Phys. Chem. C 2007, 111, 14091-14097.

51. Salimi, A.; Sharifi, E.; Noorbakhsh, A.; Soltanian, S. Direct electrochemistry and electrocatalytic activity of catalase immobilized onto electrodeposited nano-scale islands of nickel oxide. Biophys. Chem. 2007, 125, 540-548.

(C) 2009 by the authors; licensee Molecular Diversity Preservation International, Basel, Switzerland. This article is an open-access article distributed under the terms and conditions of the Creative Commons Attribution license (http://creativecommons.org/licenses/by/3.0/). 